\title{
Epidemiology and Patterns of Malignant Lymphoma in Northern Saudi Arabia
}

\author{
Abdelbaset Mohamed Elasbali ${ }^{1}$, Hisham Hussain Alharbi ${ }^{2}$, Ziad Al-Onzi ${ }^{3}$, Alneil Hamza', \\ Ezeldine Khalafalla ${ }^{1}$, Hussain Gadelkarim Ahmed ${ }^{2}$
}

\author{
${ }^{1}$ Department of Clinical Laboratory Sciences, College of Applied Medical Sciences, Jouf University, Qurayyat, KSA \\ ${ }^{2}$ College of Medicine, University of Hail, Ha'il, KSA \\ ${ }^{3}$ Department of Clinical Laboratory Sciences, College of Applied Medical Sciences, Jouf University, Skaka, KSA \\ Email: hussaingad5@gmail.com
}

How to cite this paper: Elasbali, A.M., Alharbi, H.H., Al-Onzi, Z., Hamza, A., Khalafalla, E. and Ahmed, H.G. (2018) Epidemiology and Patterns of Malignant Lymphoma in Northern Saudi Arabia. Open Journal of Blood Diseases, 8, 83-89. https://doi.org/10.4236/ojbd.2018.84009

Received: November 7, 2018

Accepted: December 3, 2018

Published: December 6, 2018

Copyright $\odot 2018$ by authors and Scientific Research Publishing Inc. This work is licensed under the Creative Commons Attribution International License (CC BY 4.0).

http://creativecommons.org/licenses/by/4.0/

\begin{abstract}
Objective: The objective of this study was to appraise the epidemiology and patterns of malignant lymphoma in Northern Saudi Arabia. Methodology: A full reportage of data regarding malignant lymphoma was retrieved from the King Khalid Hospital, Hail, Northern Saudi Arabia, comprising records of malignant lymphoma from 2009 to 2016. Results: A review of 120 blood cancers records revealed 47/120 (39.2\%) cases of lymphomas, 39 (83\%) were Non-Hodgkin lymphoma (NHL), 6 (12.8\%) were HL and 2 (4.2\%) B-cell lymphomas. The overall crude incidence rate CIR) of lymphomas (from 2009 to 2016) was 6.7 per 100,000 persons of the Hail region population. The mean CIR per year was 0.84 per 100,000 persons. Conclusion: The prevalence of malignant lymphoma is relatively higher in northern Saudi Arabia with predominance of NHL amongst elder population.
\end{abstract}

\section{Keywords}

Lymphoma, Hodgkin Lymphoma, Non-Hodgkin Lymphoma, Incidence, Saudi Arabia

\section{Introduction}

Malignant lymphoma includes a group of lymphoid neoplasms with varying genetic abnormalities, immunophenotypes and clinical features. The prevalence of Lymphoma is higher in developed countries compared to developing countries [1]. Malignant lymphoma represents approximately $3.4 \%$ of all cancers worldwide [2]. In recent years, the incidence rates of malignant lymphoma are growing up to $4 \%$ though there is a substantial steadiness of incidence rates in devel- 
oped countries [1].

Lymphoid neoplasm is classified by World Health Organization (WHO) in to Hodgkin lymphoma (HL), Non-Hodgkin lymphoma (NHL), plasm cell lymphoma and lymphoid leukemia [3] [4].

Many factors have been incriminated in the etiology of malignant lymphoma including: infections, exposure to certain chemicals, immunodeficiency (AIDS epidemic), autoimmune disease and genetic abnormalities [1].

Malignant lymphoma is a common cancer in Saudi Arabia with increased incidence among younger people. In Saudi Arabia, NHL and HL account up to $6.4 \%$ and 3.5\%, respectively of all new lymphoma cases diagnosed in 2014 [5]. Although there is a lack of literature, the disease has varied clinical presentations and pathologies, which oblige the necessity for setting up of sustained management outline [6]. The objective of this study was to appraise the epidemiology and patterns of malignant lymphoma in Northern Saudi Arabia.

\section{Materials and Methods}

This was a retrospective descriptive study conducted in King Khalid hospital, Hail, Northern Saudi Arabia (KSA) during the period from October 2016 to March 2017. A full coverage of data regarding lymphoma were retrieved from the hospital, including records of lymphoma from 2009 to 2016. The samples represent a full coverage. The obtained data were filled into a standard form prior to its filling on SPSS software for analysis. The most important parameters filled in the form were, age, sex, diagnosis.

\subsection{Ethical Consent}

The study was approved by ethical committee at the College of Medicine, University of Hail. This in addition to approval from King Khalid hospital authority.

\subsection{Statistical Analysis}

Data were analyzed using SPSS software version 16 . P value $<0.05$ was considered statistically significant. Frequencies, percentages and cross-tabulations were also produced using the software.

\section{Results}

A review of 120 blood cancers records revealed 47/120 (39.2\%) cases of lymphomas, 39 (83\%) were NHL, 6 (12.8\%) were HL and 2 (4.2\%) B-cell lymphomas. Among lymphoma cases, 27 (57.4\%) were males (20 with NHL, 5 with HL and 2 With B-cell type) and 20 (42.6\%) were females (19 with NHL and one with HL). The mean age of the patients was $45.4 \pm 25.2$ years (Table 1, Figure 1).

The overall crude incidence rate CIR) of malignant lymphomas (from 2009 to 2016) was 6.7 per 100,000 persons of the Hail region population. The overall CIR per year was 0.84 per 100,000 persons. The entire incidence rates (IR) within the 8 years, $2009(8.5 \%, \mathrm{n}=4$; IR $=0.57$ per 100,000 persons $), 2010(19 \%, \mathrm{n}=9$; IR = 
1.3), $2011(12.8 \%, \mathrm{n}=6$; IR = 0.86), $2012(10.6 \%, \mathrm{n}=5$; IR $=0.71), 2013(4.3 \%, \mathrm{n}$ $=2 ; \mathrm{R}=0.29), 2014(6.4 \%, \mathrm{n}=3 ; \mathrm{IR}=4.3), 2015(23.4 \%, \mathrm{n}=11 ; \mathrm{IR}=1.6), 2016$ $(12.8 \%, \mathrm{n}=6 ; \mathrm{IR}=0.86)$. NHL $(83 \%, \mathrm{n}=39 ; \mathrm{IR}=5.6$ per 100,000 persons $), \mathrm{HL}$ $(12.8 \%, \mathrm{n}=6$; IR $=0.86)$, B-cell lymphoma $(4.3 \%, \mathrm{n}=2 ; 0.29)$ (Table 1 , Figure 1).

The outcomes of the patients included; normal discharge 42.6\% ( $\mathrm{n}=20$ ), DAMA 29.8\% $(\mathrm{n}=14)$, transferred 4.3\% $(\mathrm{n}=2)$, and died 23.4\% $(\mathrm{n}=11)$. Death included $8 / 11$ (72.7\%) with NHL, 2/11 (18.2\%) HL and $1 / 11$ (9.1\%) B-lymphoma, as described in Table 2, Figure 2.

Table 1. Lymphoma type by age, sex and the year of admission.

\begin{tabular}{|c|c|c|c|c|c|}
\hline Variable & Category & NHL & $\mathrm{HL}$ & B-cell lymphoma & Total \\
\hline \multirow[t]{2}{*}{ Sex } & Males & 20 & 5 & 2 & 27 \\
\hline & Females & 19 & 1 & 0 & 20 \\
\hline \multicolumn{6}{|l|}{ Age } \\
\hline & $<18$ years & 1 & 1 & 0 & 2 \\
\hline & $19-30$ & 6 & 4 & 0 & 10 \\
\hline & $31-40$ & 5 & 1 & 0 & 6 \\
\hline & $41-60$ & 7 & 0 & 1 & 8 \\
\hline & $61-75$ & 15 & 0 & 0 & 15 \\
\hline & $76+$ & 5 & 0 & 1 & 6 \\
\hline & Total & 39 & 6 & 2 & 47 \\
\hline \multicolumn{6}{|l|}{ Years } \\
\hline & 2009 & 2 & 1 & 1 & 4 \\
\hline & 2010 & 7 & 2 & 0 & 9 \\
\hline & 2011 & 6 & 0 & 0 & 6 \\
\hline & 2012 & 5 & 0 & 0 & 5 \\
\hline & 2013 & 0 & 2 & 0 & 2 \\
\hline & 2014 & 2 & 1 & 0 & 3 \\
\hline & 2015 & 10 & 0 & 1 & 11 \\
\hline & 2016 & 6 & 0 & 0 & 6 \\
\hline & Total & 39 & 6 & 2 & 47 \\
\hline
\end{tabular}

Table 2. Lymphoma types by outcomes.

\begin{tabular}{ccccc}
\hline Outcomes & NHL & HL & B-cell lymphoma & Total \\
\hline Normal discharge & 16 & 3 & 1 & 20 \\
DAMA & 14 & 0 & 0 & 14 \\
Transferred & 1 & 1 & 0 & 2 \\
Died & 8 & 2 & 1 & 11 \\
Total & 39 & 6 & 2 & 47 \\
\hline
\end{tabular}




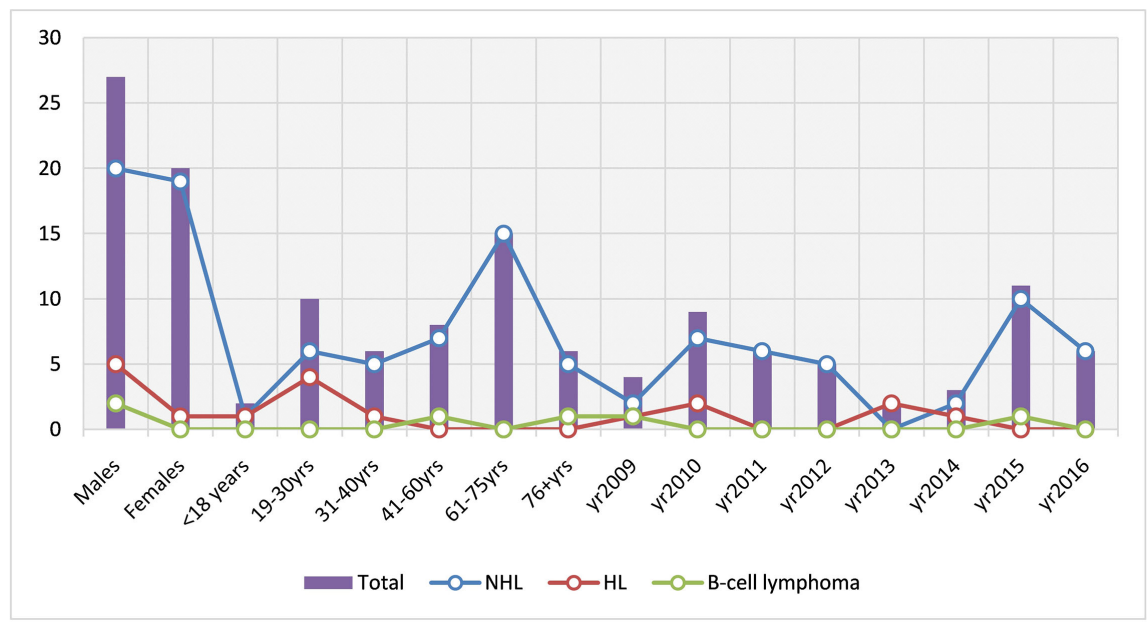

Figure 1. Lymphoma type by age, sex and year of admission.

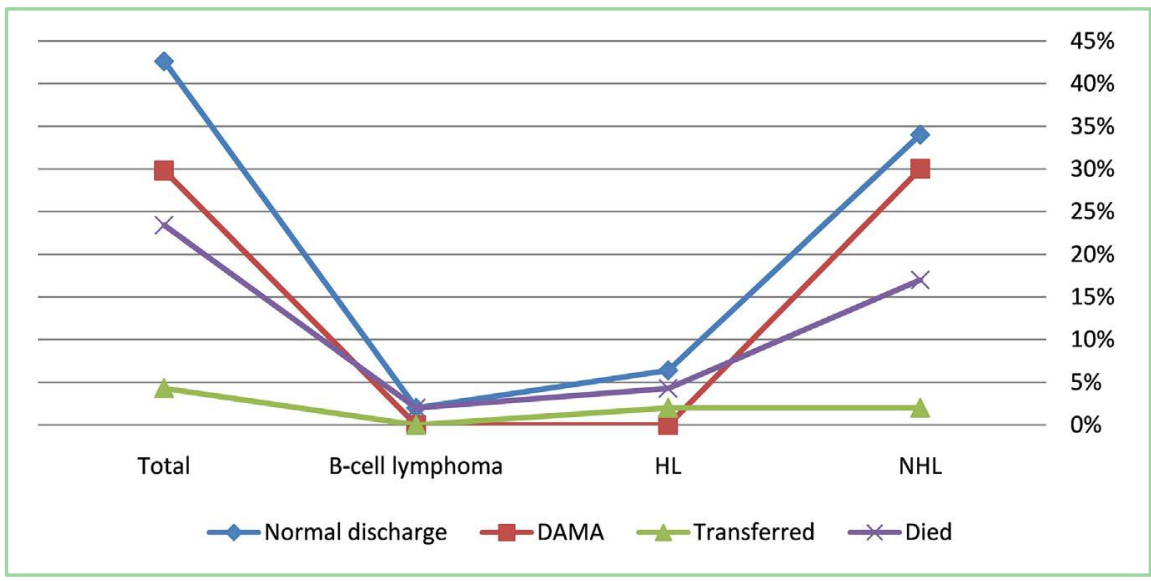

Figure 2. Lymphoma types by outcomes.

\section{Discussion}

The incidence rates of malignant lymphoma greatly vary across different geographical areas worldwide, in respect to the availability of muti-factorial etiological factors. The findings of the present study exposed an overall crude incidence rate (CIR) of malignant lymphoma (from 2009 to 2016) of 6.7 per 100,000 persons of the Hail region population (Northern Saudi Arabia). With lack of data from Saudi Arabia, the few available studies were focusing in partial lymphoma issues. One of these studies reported malignant lymphoma as the second most common cancer after the breast irrespective of sex [7]. Another study obtained data (about Childhood cancer in Saudi Arabia) from the Saudi Cancer Registry from 1999 to 2008, has reported that, the commonest cancers were leukemia (34.1\%) trailed by malignant lymphoma (15.2\%) [8].

NHL represented the bulk of cases in series (83\%) with CIR of 5.6 per 100,000 persons. An earlier study from Saudi Arabia has reported NHL as the second most prevalent cancer in the country with a significant predominance among male population [9] [10]. One medical center from Saudi Arabia has reported 
that the prevalence of NHL during the period from 1975 to 2011 was 7.6\% [11]. In 2018, it was found that the incidence of NHL in neighboring Gulf countries including Yemen, Oman, Qatar, and United Arab Emirates were 7.1\%, 6.9\%, 6.1\%, and $3.31 \%$, respectively compared to Saudi Arabia (5.89\%, both sex and all ages), as estimated by the International Agency for Research on Cancer (IARC) [12].

In this contemporary data, HL denoted $12.8 \%$ of all lymphoma cases with CIR of 0.86 per 100,000 persons. The GLOBCOAN 2018 reported has indorsed an incidence rate of $2.73 \%$ for $\mathrm{NH}$ in Saudi Arabia, which was similar to that reported from Yemen (3.75\%) and higher that reports from Qatar (3.37\%) and United Arab Emirates (1.92\%) [12]. In 2012, it was reported that the incidence of HL in Saudi Arabia was 3.2\% of all cancer cases [13].

The comparatively higher incidence of lymphoma in Saudi Arabia may ratify the existence of some interconnected etiological factors. With scarcity of evidences pertained to etiology of lymphoma in Saudi Arabia, limited studies addressed some causative factors such as, Epstein Barr Virus (EBV). Although it was reported that EBV has a role in etiology of lymphoma in Saudi Arabia, it was suggested that some hidden factors lay under the increased incidence of malignant lymphoma including genetic susceptibility [14]. A population based study from neighboring Qatar reported high seroprevalence of EBV (95\%), with a high viremia amongst studied group (52.6\%), which was found to increase with age [15]. Other etiological factors including HIV, Immunosuppression and exposure to diverse chemicals were vaguely deliberated in Saudi former literature.

Malignant lymphoma was predominantly perceived in males compared to females. Studies from Saudi Arabia and other countries have shown similar findings [16] [17]. In this study, approximately $83.3 \%$ of the cases of HL were males, which is very high percentage compared to other reports [16].

NHL was significantly noted among elder population $>61$ years. Such verdicts were earlier reported [18]. On the other hand, the bulk of HL cases were below the age of 30 years. Such results were previously reported [19] [20].

The outcomes of patients with malignant lymphoma in this series disclosed a relatively higher death rate $23.4 \%$. However, many factors determine the anticipated outcomes, which were not applicable in this study.

The limitation of the present study included its retrospective settings, which minimized the some essential data.

\section{Conclusion}

The prevalence of malignant lymphoma is relatively higher in northern Saudi Arabia with predominance of NHL amongst elder population. Further studies on the factors subsidizing the increased incidence of lymphoma are deemed important and urgent.

\section{Conflicts of Interest}

The authors declare no conflicts of interest regarding the publication of this paper. 


\section{References}

[1] Huh, J. (2012) Epidemiologic Overview of Malignant Lymphoma. Korean Journal of Hematology, 47, 92-104. https://doi.org/10.5045/kjh.2012.47.2.92

[2] International Agency for Research on Cancer (2008) CANCER Mondial. International Agency for Research on Cancer, Lyon.

[3] Swerdlow, S.H. (2007) WHO Classification of Tumours of Haematopoietic and Lymphoid Tissues. 4th Edition, IARC Press, Lyon.

[4] Swerdlow, S.H., Campo, E., Pileri, S.A., et al. (2018) The 2016 Revision of the World Health Organization Classification of Lymphoid Neoplasms. Blood, 127, 2375-2390. https://doi.org/10.1182/blood-2016-01-643569

[5] Riyadh: Ministry of Health (2014) Saudi Cancer Registry Annual Report.

[6] Rauf, M.S., Akhtar, S. and Maghfoor, I. (2015) Changing Trends of Adult Lymphoma in the Kingdom of Saudi Arabia-Comparison of Data Sources. Asian Pacific Journal of Cancer Prevention, 16, 2069-2072. https://doi.org/10.7314/APJCP.2015.16.5.2069

[7] El Hag, I.A., Katchabeswaran, R., Chiedozi, L.C. and Kollur, S.M. (2002) Pattern and Incidence of Cancer in Northern Saudi Arabia. Saudi Medical Journal, 23, 1210-1213.

[8] Al-Mutlaq, H.M., Bawazir, A.A., Jradi, H., Al-Dhalaan, Z.A. and Al-Shehri, A. (2015) Patterns of Childhood Cancer Incidence in Saudi Arabia (1999-2008). Asian Pacific Journal of Cancer Prevention, 16, 431-435. https://doi.org/10.7314/APJCP.2015.16.2.431

[9] Alghamdi, I.G., Hussain, I.I., Alghamdi, M.S., Dohal, A.A., Alghamdi, M.M. and El-Sheemy, M.A. (2014) Incidence Rate of Non-Hodgkin's Lymphomas among Males in Saudi Arabia: An Observational Descriptive Epidemiological Analysis of Data from the Saudi Cancer Registry, 2001-2008. International Journal of General Medicine, 7, 311-317. https://doi.org/10.2147/IJGM.S63645

[10] Saudi Cancer Registry (2008) Cancer Incidence Report in Saudi Arabia. Ministry of Health, Riyadh.

[11] King Faisal Specialist Hospital and Research Centre (2011) Tumor Registry Annual Report. Tumor Registry, Riyadh.

[12] Globocan. The Global Cancer Observatory (GCO) (2018) Cancer Today; Population Fact Sheets. http://gco.iarc.fr/today/fact-sheets-populations

[13] Bazarbashi, S., Al Eid, H. and Minguet, J. (2017) Cancer Incidence in Saudi Arabia: 2012 Data from the Saudi Cancer Registry. Asian Pacific Journal of Cancer Prevention, 18, 2437-2444.

[14] Al-Kuraya, K., Narayanappa, R., Al-Dayel, F., et al. (2006) Epstein-Barr Virus Infection Is Not the Sole Cause of High Prevalence for Hodgkin's Lymphoma in Saudi Arabia. Leukemia \& Lymphoma, 47, 707-713. https://doi.org/10.1080/10428190500286879

[15] Smatti, M.K., Yassine, H.M., AbuOdeh, R., et al. (2017) Prevalence and Molecular Profiling of Epstein Barr virus (EBV) among Healthy Blood Donors from Different Nationalities in Qatar. PLoS One., 12, e0189033. https://doi.org/10.1371/journal.pone.0189033

[16] Shafi, R.G., Al-Mansour, M.M., Kanfar, S.S., et al. (2017) Hodgkin Lymphoma Outcome: A Retrospective Study from 3 Tertiary Centers in Saudi Arabia. Oncology Research and Treatment, 40, 288-292. https://doi.org/10.1159/000460819 
[17] Muto, R., Miyoshi, H., Sato, K., et al. (2018) Epidemiology and Secular Trends of Malignant Lymphoma in Japan: Analysis of 9426 Cases According to the World Health Organization Classification. Cancer Medicine, 7, 5843-5858. https://doi.org/10.1002/cam4.1805

[18] Kyriakou, C., Boumendil, A., Finel, H., et al. (2018) The Impact of Advanced Patient Age on Mortality after Allogeneic Hematopoietic Cell Transplantation for Non-Hodgkin Lymphoma: A Retrospective Study by the European Society for Blood and Marrow Transplantation Lymphoma Working Party. Biology of Blood and Marrow Transplantation, pii: S1083-8791(18)30527-5.

https://doi.org/10.1016/j.bbmt.2018.08.025

[19] Mauz-Körholz, C., Metzger, M.L., Kelly, K.M., et al. (2015) Pediatric Hodgkin Lymphoma. Journal of Clinical Oncology, 33, 2975-2985.

https://doi.org/10.1200/JCO.2014.59.4853

[20] Garciaz, S., Coso, D., Brice, P. and Bouabdallah, R. (2016) Hodgkin and Non-Hodgkin Lymphoma of Adolescents and Young Adults. Bulletin du Cancer, 103, 1035-1049. https://doi.org/10.1016/j.bulcan.2016.10.011 